\title{
Waist Curve Forming As An Adjuvant Procedure In Abdominoplasty
}

\author{
Emad K. Bayumi \\ Crimean Medical Academy Named After S.I. Georgievsky Crimean Federal University Named After V.I. \\ Vernadsky, Crimea, Russia
}

\begin{abstract}
:
Introduction: Abdominoplasty is a commonly requested procedure for many reasons, including the concerns of an aging population determined to maintain a youthful physique, women intent on restoring their pre pregnancy appearance, the rise in massive weight loss patients who are seeking to remove the stigmata of residual excess skin from weight loss. The goal of abdominal contour surgery is the aesthetic improvement of the affected soft tissue layers of skin, fat, and muscle through the least conspicuous incision feasible.

In fact, problems that generate dissatisfaction and complaints from patients with classic abdominoplasty are primarily fullness of the flanks and epigastric areas 2

The author in this study described a new and simple technique for Waist curve forming

Patients and methods: The present study included 50 cases, who were subjected to abdominoplasty with waist curve enforcement new technique in Crimean Medical Academy named after S.I. Georgievsky Crimean Federal University named after V.I. Vernadsk Russia in department of general and gastrointestinal surgery. The study started from January 2012 to may 2016. End points: The primary end point of the study was the aesthetic appearance of the waist curve and the second end point was patient satisfaction of the operative outcome.

Results: Over 50 cases of abdominoplasty, we performed a new and simple technique for curve waist. There were 50 females with age ranging from 28 to 52 years with the mean value as $40 \pm 7.35$ years.

Conclusion: The technique for abdominoplasty with waist curve forming of the presented in the present study is a simple technique without complications, with long term success and good aesthetic appearance The new constructed waist curves exhibits appropriate features curved waist and avoids the appearance of fullness of the flanks and epigastric areas and patient dissatisfaction as T mesh laid enforcement increases by time as fibroses occur.
\end{abstract}

Keywords: Waist curve, abdominoplasty, new technique.

\section{Introduction}

Abdominoplasty is an important and common operation in aesthetic surgery. Since its original recorded description, several technical improvements have been made. Fundamentally, however, there has been no change in the essential concept of extensive undermining almost to the costal margin, followed by appropriate resection and closure[1,2,3]. Abdominoplasty in its most primitive form has existed for more than 100 years [4,5]. Functional abdominoplasty was first described by Kelly [6,7] in 1899 and later popularized by Pitanguy, who introduced the low transverse (i.e., bikini line) incision for cosmetic purposes in 1967. Following this period, abdominoplasty became a routine operation with growing popularity 5,8$]$.

Multiple objectives have to be considered when performing an abdominoplasty: [5] removal of excess fat, skin, and stria; [4] short, hidden scar, ideally placed within the bikini line; [6] flattening and tightening of the abdomen while concomitantly creating a harmonious contour of the periumbilical area and flanks. Furthermore, the conducted technique should provide a tension-free closure, especially in the midline, as this area displays an alarming low rate of perfusion [6,7], resulting in skin necrosis when subject to tension upon closure [6]. Modern abdominoplasty techniques were developed during the last 40 years [8] addressing not only skin and subcutaneous tissue, but also the muscular abdominal wall to maximize aesthetic outcome [1]. Despite the multiple modifications and variations, the surgical principles have remained largely alike [9]. Standard abdominoplasties include a transverse lower abdominal incision, wide undermining of the skin and subcutaneous tissue up to the costal margins, tightening of the abdominal musculature with correction of rectus muscle diastasis, resection of redundant abdominal skin and subcutaneous tissue, umbilical repositioning, and skin closure with hips flexed [8,9].

There are many techniques for curve waist forming, the author in this study described a new and simple technique. 


\subsection{Patients}

\section{Patients And Methods}

The present study included 50 patients subjected to abdominoplasty with waist forming enforcement in Crimean Medical Academy named after S.I. Georgievsky Crimean Federal University named after V.I. Vernadsk Russia in department of general and gastrointestinal surgery. The study started from January 2013 to May 2016. Written consents were obtained from all patients before the study. The steps of operative interferences were explained to all patients. The local ethics committee had approved all operative procedures. Ethical approval for this study department of general and gastrointestinal surgery Crimean Medical Academy named after S.I. Georgievsky, Crimean Federal University named after V.I. VernadskRussia.

\subsection{Operative Techniques:}

Preoperative assessment and designing the incision are usually performed as shown in figure 1. A lower abdominal crease incision as the procedure of dermo-lipectomy and complete flap elevation were performed till the xyphoid process with minimal dissection of the lateral supra-umbilical region. Undermining is done in an inverted V-type fashion. The undermining in this fashion keeping us away from the costal margin, preserving the blood supply coming to the upper flap from the lateral side (segmental perforators). The hernia defect is repaired anatomically and if weak divercation of rectus muscles keel repair with proline running interlocking suture from xephy sternum till suprapubic, then the mesh is monoaryl composite partially absorbed type (poliglecaprone 25/polypropylene $6 \times 6$ inch).

Fashioning of the monocryl composite proline mesh as cross shape longitudinal with width $8-10 \mathrm{~cm}$ from the xephesternum to suprapubic area and in the area around umbilicus transvers with width $5-10 \mathrm{~cm}$ reaching the flanks \{figure 2 \} to make the proline stitch started from the thoraco lumber fascia proline stitch with plication throw continues stitches to end in proline mesh Tung mad as continues suture to press the flanks as built \{figure 3 \}. To achieve a narrow waist increase by time as fibrosis, more interrupted sutures were fixed most laterally and strengthen the rectus sheath with two longitudinal sheets of meshes \{Figure 4\}. Light dressing is used. A compression garment is applied immediately following the operation. Early ambulation is important to avoid deep venous thrombosis. The suction drains are removed when the daily drainage is less than $10 \mathrm{cc}$. Sutures removed 10 days following the operation. \{figure $5 \mathrm{~A}, \mathrm{~B} \& \mathrm{C}$ \}.

\subsection{End Points:}

The primary end point of the study was the aesthetic appearance of the waist curve after the $10^{\text {th }}$ day of post-operative period and the second end point was patient satisfaction of the operative outcome.

\section{Results}

Over 50 cases of abdominoplasty with waist forming enforcement with the new and simple technique were enrolled to the study. There were 50 females with the age ranging from 28 to 52 years with the mean value as $40 \pm 7.35$ years. The esthetic appearance and patient satisfactionwherestudded in our patients.

\begin{tabular}{|l|l|l|}
\hline & Accepted & Not Accepted \\
\hline Aesthetic Effect & 40 & 10 \\
\hline Patient Effect & 36 & 14 \\
\hline
\end{tabular}

$80 \%$ aesthetic effect accepted

$72 \%$ patient satisfactory accepted

\section{Discussion}

Following childbirth, most women complain of remaining skin in the central region of their abdomen and stretch marks and laxity are also frequent concerns. Liposuction may be a line of treatment for thinner women with minor skin excesses and fat deposits, while full abdominoplasty may be suitable for obese women with severe skin laxity, umbilical ptosis, and abundant abdominal fat deposits [10]. 
However, abdominoplasty has become a frequent, appearing to be technically easy operation but nevertheless a source of potentially annoying problems andcomplications clearly affecting the aesthetic results and the satisfaction rate of the patients. The problems that generate complaints from patients and dissatisfaction with classic abdominoplasty are: Fullness of epigastrium, fullness of flanks with or without dog-ears, lack of waist definition, depressed scar and hanging skin over the incision line, large bulging and ptotice mons pubis and visible scar beyond underwear coverage. Careful analysis of these problems relates them to operating on thick skin with excess fat, design of the skin resection pattern, lack of multiple layer closure and not tackling the mons pubis region. In presence of excess fat and regardless of how tight the skin may be pulled, over time, there will be some loss of shape or contour $[11,12,13]$.

Liposuction is one of the most popular cosmetic surgery procedures currently performed by plastic surgeons around the world. It must be clear at the outset that liposuction is not primarily a modality for weight loss, it is meant to be a body contouring procedure and therefore the inherent limitations and safety issues related to this must always be respected if complications and unfavorable results are to be avoided as far as possible. [14]

More recent advances in body contouring have involved the use of ultrasonic energy to aid in the removal of the fat. As it turns out, certain tissues of the body will absorb certain frequencies of ultrasonic energy in a specific way. We must remember that one limitation of liposuction is that the skin must have the ability to contract and conform over the new contour that is produced. If the skin or tissue is too lax, it will shrivel up or hang loose. This can be very unsightly [15].

By far the most common procedure in body contouring is liposuction [16] while our new maneuver a simple technique of using the anatomical repairs based from lumber facia to rectus facia using the mesh to compress and reduce the waist and keep nice curve and with time fibrosis increase the waist $[15,16,17]$.

Liposuction is associated with a variety of complications, most of which can be avoided. These complications can be broadly categorized into three groups. Swelling or oedema is anticipated after almost every liposuction procedure as a normal reaction of the human tissues to the actual surgical trauma of the cannula similar to the response of sterile inflammation that occurs after any trauma. The collection of serous fluid in a liposuctioned area may be due to excessive tissue trauma, following aggressive oversuctioning of a single area with extensive breaking of the fibrous tissue network leading to a single cavity formation or it may be due to significant damage to the lymphatics [18].

The aesthetic results of this technique were assessed clinically and photographically and considered satisfying by both the surgeon and patients. Reconstruction of the waist is a procedure that refines the outcomes of abdominal surgery and its absence significantly affects the aesthetics of the abdomen, making it an essential part of the anatomy. The aesthetic appeal of the abdomen is directly related to good waist conformation. The absence or pendulous or fullness of the flank is both cosmetically and psychologically distressing to patients and the goal of aesthetically pleasing waist curved is to create a neo umbilicus with sufficient depth, good morphology, with natural-looking superior hooding and minimal scarring [9]. Surgery performed with this technique was considered quite safe; there were no complications during surgery, and postoperative complications were treated appropriately. Evaluating the patients' emotional attitude and clarifying the possibilities and limitations of this procedure increase the chance of meeting the patients' expectations. This contributes to improved self-esteem, happiness, a sense of well-being, and balance between physical and emotional health. Where $80 \%$ aesthetic effect is accepted and72\% patient satisfactory is accepted.

\section{Conclusion}

The technique for reconstruction of the of the waist present study is a simple technique without complications, with long term success and good aesthetic appearance and a higher chance of meeting the patients' expectations, by $80 \%$ acceptance of aesthetic effect and $72 \%$ patient satisfactory acceptance. This contributes to improved self-esteem, happiness, a sense of well-being, and balance between physical and emotional health.

\section{References}

[1]. Yousif NJ, Lifchez SD, Nguyen HH. Transverse Rectus Sheath Plication in Abdominoplasty. PlastReconstrSurg 2004, 114:778784.

[2]. Heller JB, Teng E, Knoll BI, Persing J . Outcome Analysis of Combined Lipoabdominoplasty versus Conventional Abdominoplasty. PlastReconstrSurg 2008, 121: 1821-1829.

[3]. Shermak MA, Rotellini-Coltvet LA, Chang D . Seroma Development following Body Contouring Surgery for Massive Weight Loss: Patient Risk Factors and Treatment Strategies. PlastReconstrSurg 2008, 122: 280-288.

[4]. Kelly HA. Report of gynecologic diseases (excessive growth of fat). Johns Hopkins Med J 1899, 10:197-201.

[5]. Pitanguy I Abdominal lipectomy: An approach to it through analysis of 300 consecutive cases. PlastReconstrSurg 1967, 40:384391.

[6]. Le Louarn C, Pascal JF High Superior Tension Abdominoplasty. AesthPlastSurg 2000, 24:375-381.

[7]. Momeni A, Heier M, Bannasch H, Torio-Padron N, Stark GB (2008) The "Rising-Sun-Technique" in Abdominoplasty. Ann PlastSurg 60: 343-348 
[8]. Mayr M, Holm C, Ho fter E, Becker A, Pfeiffer U, Mühlbauer W (2004). Effects of aesthetic abdominoplasty on abdominal wall perfusion: a quantitative analysis. PlastReconstr Surg. 114:1586 -1594.

[9]. Friedland JA, Maffi TR . MOC-PSSM CME Article: Abdominoplasty. Plast. Reconstr. Surg. 2008, 121: 1-11

[10]. Lockwood T. High-lateral-tension abdominoplasty with superficial fascial system suspension. PlastReconstrSurg 1995, 96: 603615 .

[11]. Saldanha OR, Azevedo SF, Delboni PS, SaldanhaFilho OR, Saldanha CB, Uribe LH. Lipoabdominoplasty: the Saldanha technique. ClinPlast Surg. 2010;37(3):469-481.

[12]. Stewart KJ, Stewart DA, Coghlan B, Harrison DH, Jones BM, Waterhouse N. Complications of 278 consecutive abdominoplasties. J PlastReconstr Aesthetic Surg. 2006;59 (11):1152-1155.

[13]. Dixit VV, Wagh MS. Unfavourable outcomes of liposuction and their management. Indian Journal of Plastic Surgery: Official Publication of the Association of Plastic Surgeons of India. 2013;46(2):377-392. doi:10.4103/0970-0358.118617.

[14]. Kim J. and Stevenson T.R.: Abdominoplasty, liposuction of the flanks, and obesity: Analyzing risk factors for seroma formation. Plast. Reconstr. Surg., 117: 773, 2006

[15]. Hafezi F. and Nouhi A.: Safe abdominoplasty with extensive liposuctioning. Ann. Plast. Surg., 57: 149, 2006.

[16]. Graf R., de Araujo L.R., Neto L.G., Pace D.T. and Cruz G.A.: Lipoabdominoplasty: Liposuction with reduced undermining and traditional abdominal skin flap resection. Aesthetic Plast. Surg., 30: 1, 2006.

[17]. Shiffman MA. Prevention and treatment of liposuction complications. In: Shiffman MA, Di Giuseppe A, editors. Liposuction Principles and Practice. 1st ed. New York: Springer; 2006. pp. 333-41

Preoperative photos showing patients with anterior and lateral views.

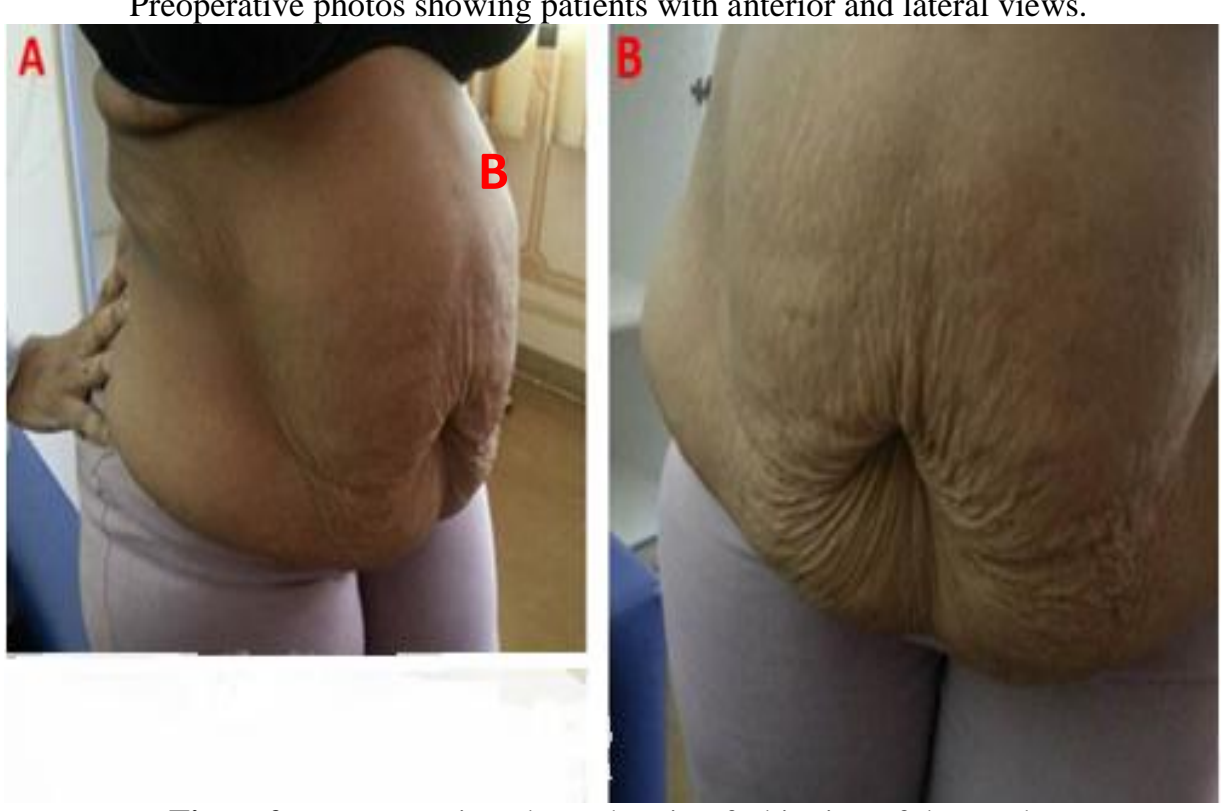

Figure2: Intraoperative photo showing fashioning of the mesh.

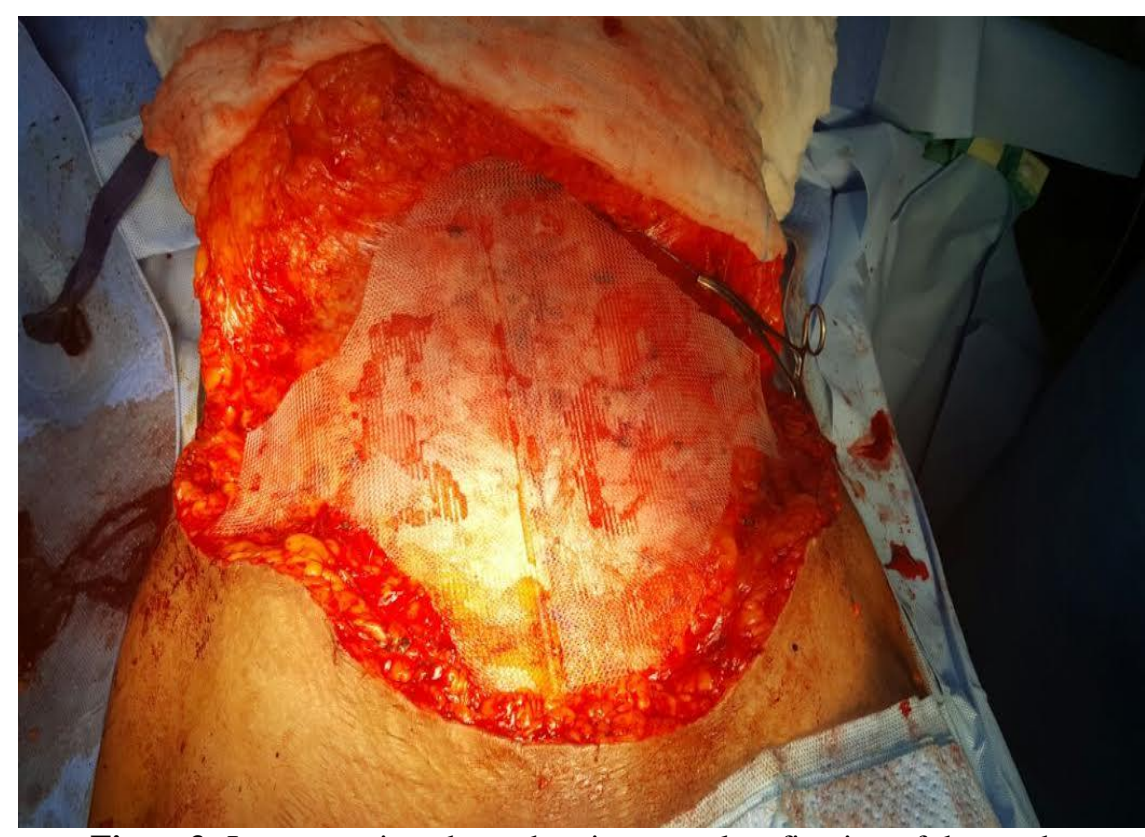

Figure3: Intraoperative photo showing complete fixation of the mesh. 


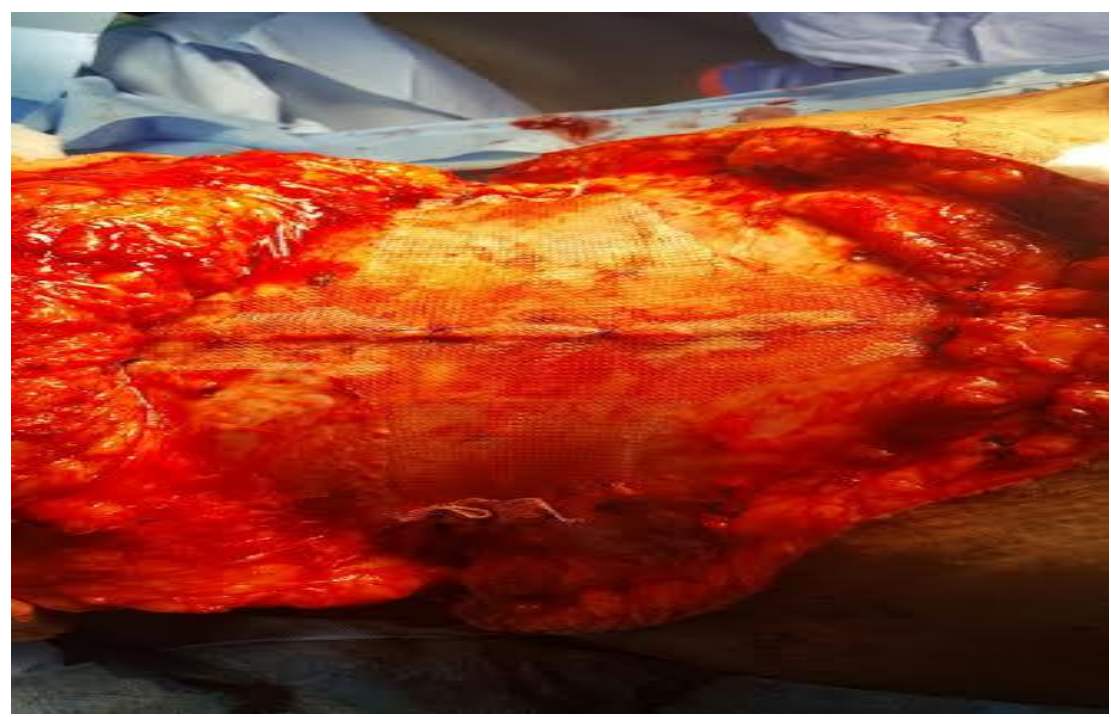

Figure4: Intraoperative photo showing more interrupted sutures were fixed most laterally to achieve a narrow waist.

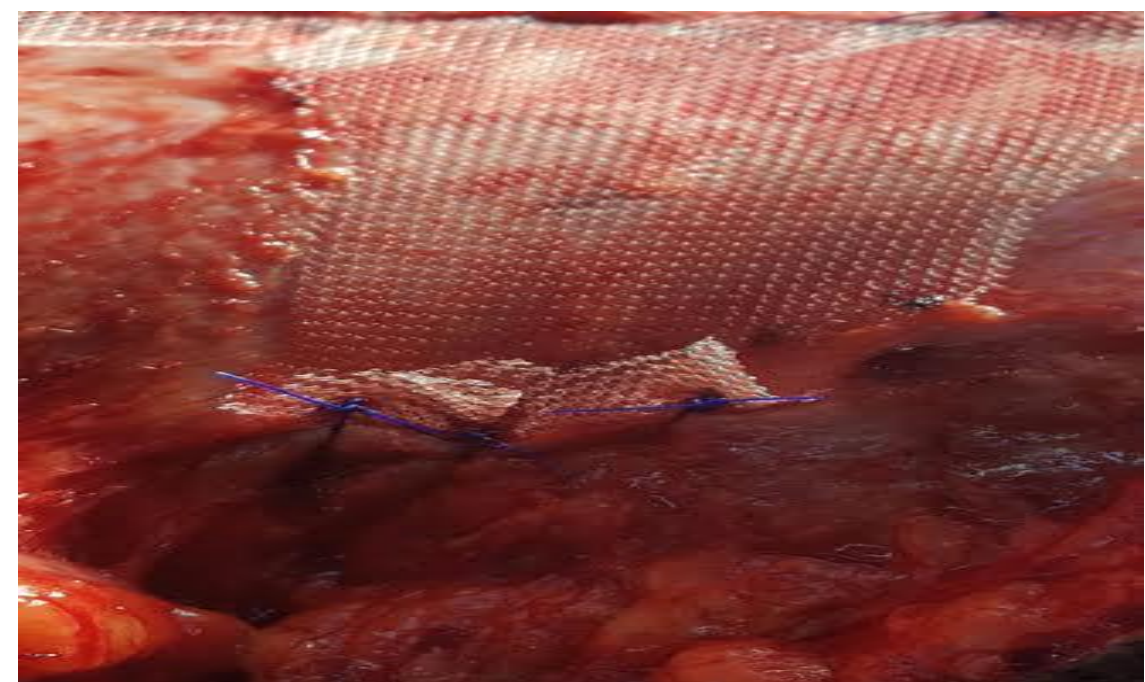

Figure5: Postoperative waste result.

A

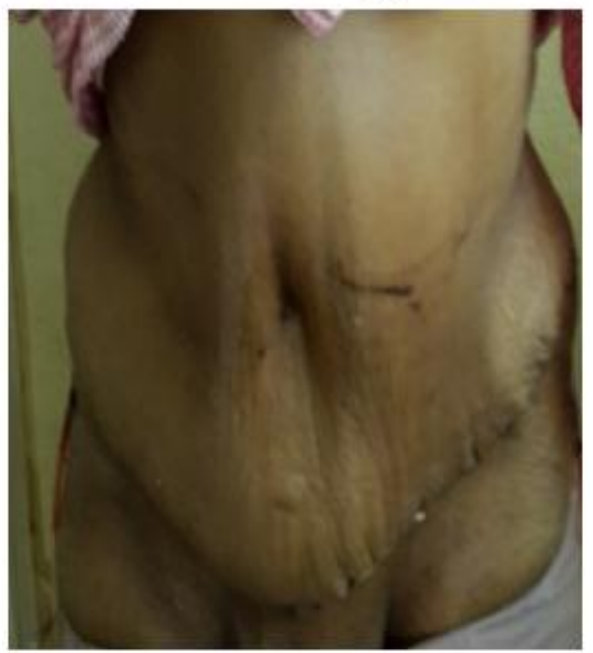

B

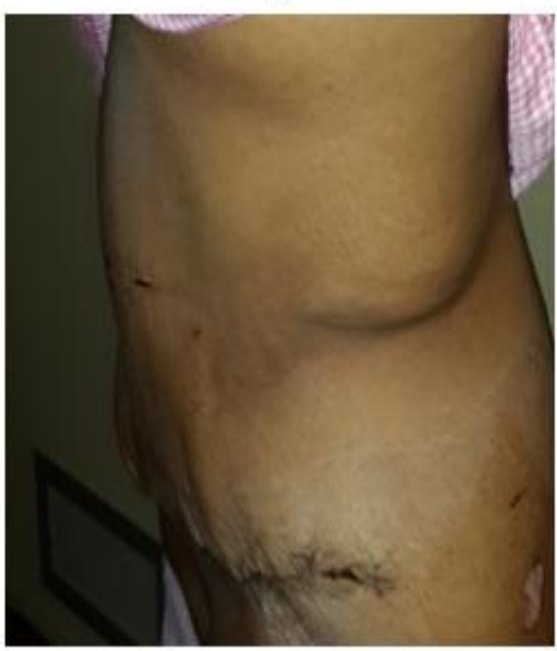

